\title{
COST REDUCTION BY MEANS OF ALTERNATIVE SOLUTIONS
}

In some projects the offered remuneration is lower than the estimated total costs. There are three possibilities to handle this problem. The first two is either to resign from the implementation, or to accept it knowing that we will loose money, but can regain it later in another project. In this latter case we have to determine the optimal resource allocation with minimal total cost. In the scheduling phase we can use some cost minimizing method. After that we can determine the lower and the upper bound of the start time of the activities. The next step is to determine a feasible solution and then the optimal resource allocation. The third possibility is to accomplish the project and find alternative implementation of activities that requires lower variable costs. During the search for alternative implementation of activities the most important aspect should be the quality, the decrease of costs is only the second one. If the total cost is lower than the offered remuneration we have to find the optimal resource allocation for the problem. Sometimes we cannot find alternative implementations, e.g. when a minimal quality level is given. In this case we can decide to either refuse or accept the implementation based on the extent of possible loss of money.

\section{Introduction}

In the course of planning and implementation of projects it occurs frequently that after the preliminary calculation of the optimal resources allocation - in order to obtain minimal total cost - a project can not be realized at a price which is expected by the inviter of the tender.

In the following study we present a method by which, in case of a delimited maximal budget, we are able to determine the schedule, cost need and resource requirements of a project to be implemented with the highest possible quality.

\section{Alternative solutions}

When in case of optimal resource allocation employed for minimal total cost during the preliminary calculation the expenses are higher than the budget earmarked for the implementation of the project then we have three options: we either give up the implementation of the project or we realize the project with losses or we replace some activities by new ones in order to reduce the costs. In the course of our analysis we will not consider the first option any longer since in this case we lose this business and there is no sense in making any further optimal resource planning. The second option is sometimes undertaken when they estimate that in spite of the initial losses the deficit will return during the implementation of the subsequent projects. In this case the allocation of the resources which is optimal for the given target function involving a minimal total cost shall be determined. (For the method refer to the study: Optimal resource allocation of active projects).
It is the third option we are going to study in this paper, i.e. we replace some activities to be realized with other activities in order to reduce the expenses.

In case of this third option, first of all, we have to make a list of alternative implementations of individual activities.

We should take into account three criteria when setting our objective (the order of the criteria also gives a priority during selection):

1. first of all, we have to perform the given activities with the best possible quality

2. next the introduction of the alternative solution shall involve the greatest reduction costs

3. in the third place, the lead time of the activity and the demand for resources shall change at the slightest possible extent (they preferably get reduced).

In addition to these criteria, for each activity a minimal quality requirement can be specified which in any case shall be met under the terms of the contract.

It is practical to arrange the alternative solutions belonging to a given activity in accordance with these criteria. From the list of the possible alternative activities to be implemented we should eliminate the ones which do not meet the quality requirements. During selection we reschedule the activities by using the alternative solution which is most suitable for the purpose and try to find the optimal solution again. The search of the alternative solutions is a selection problem determined for several target functions. We can find the optimal solution by the Branch \& Bound method or by means of dynamical programming.

\footnotetext{
* Zsolt Tibor Kosztyán, Zoltán Perjés, Andrea Bencsik

Department of Management, University of Veszprém, E-mail: kzst@vision.vein.hu
} 


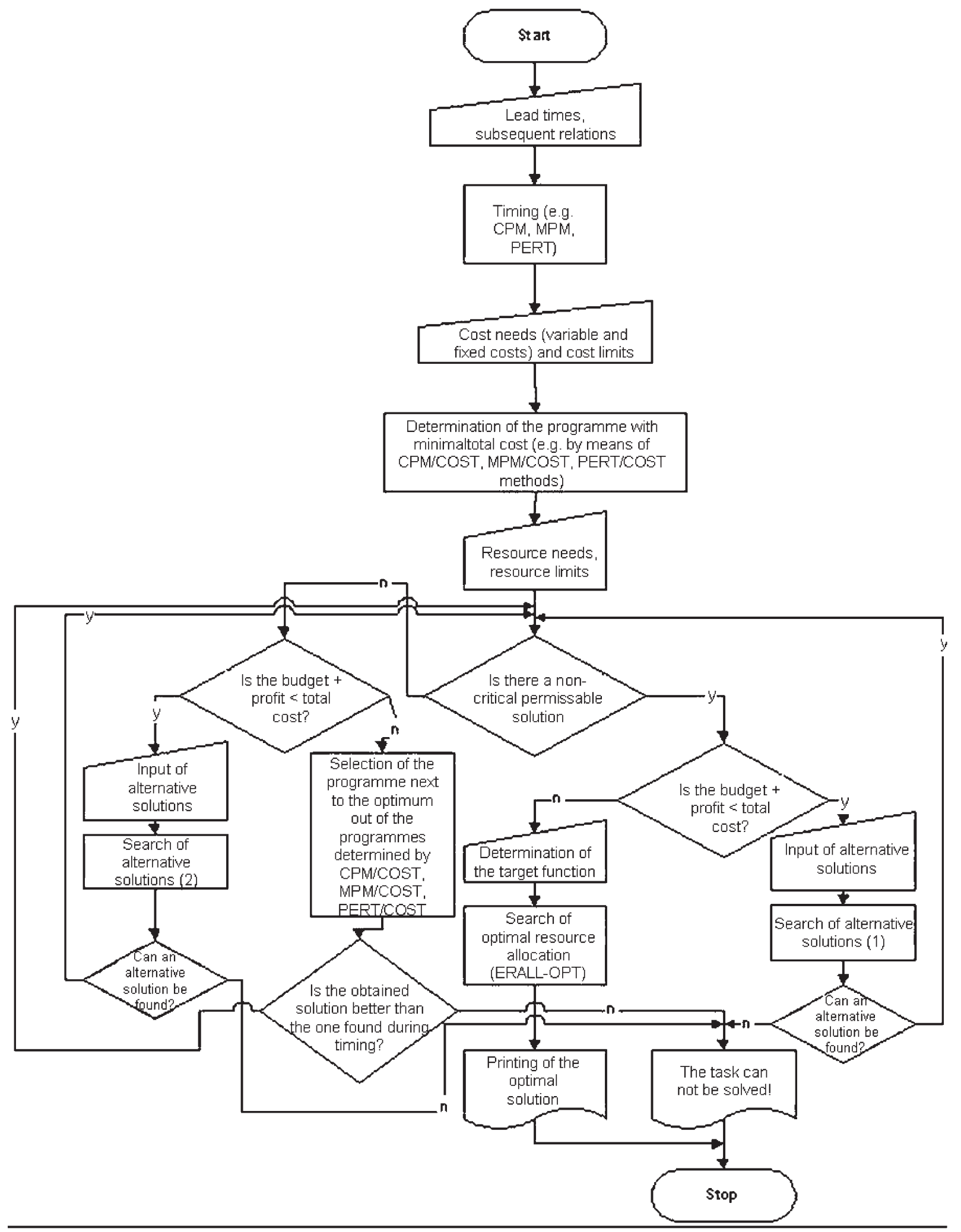

Fig. 1 Search of alternative solutions 


\subsection{The search of alternative solutions}

The starting point of the method is the cost-optimal permissible allocation of resources or which is optimal for a given target function. We can find such a solution by determining a schedule with minimal total cost at the outset. If a non-critical permissible solution for this schedule is in existence, i.e. there is a permissible solution which does not amend the length of the critical path or does not overstep the limit of the resources then in accordance with the target function defined in Chapter 2 we should find alternative activities in a manner that during the employment of the alternative activities a non-critical solution must exist. If there is a non-critical solution then there is an optimal resources allocation as well and it can be found by a limited number of steps (see: Optimal resource allocation of active projects).

The method is illustrated on the following flowchart. In the first place we should make a timing to cope with the task. It requires the knowledge of the lead times and subsequent relations of the activities. We can carry out the timing by any method used in practice (CPM, MPM, Pert etc). Then we have to determine a solution with minimal total cost. This can be performed by any costoptimising method used in practice (CPM/COST, MPM/COST, PERT/COST and so on). The utilization of the method requires the knowledge of cost needs, cost limits and the lead time - cost need functions. We estimate the lead time - cost need functions or, in case of production of small series, we determine them by means of statistical methods with a given probability. (For the details of the determination refer to the study: Handling of uncertainty in the production management of small series). Then we should examine whether there is a non-critical permissible solution. If there is such a solution then, according to the previous paragraph, the resource allocation optimal for the given target function can be determined by a limited number of steps. On the other hand, if there is not such a solution then we have to find an alternative solution here as well, but the 2 and 3 priority points of the target functions shown in the previous chapter are to be switched.

The objective remains that we have to carry out the given activities with the highest possible quality, but in order to find a non-critical solution we have to realize an activity of that sort in an alternative manner, which has a smaller resource need and/or shorter lead time.

If there is no other alternative solution then out of the solution list drawn up by the CPM/COST, MPM/COST and PERT/COST methods we have to pick out the solution which is next to the programme with minimal total cost need and to carry out the examination once again.

Let us take a look at the following example:

Let us examine a project with the following activities which are shown in the table below.

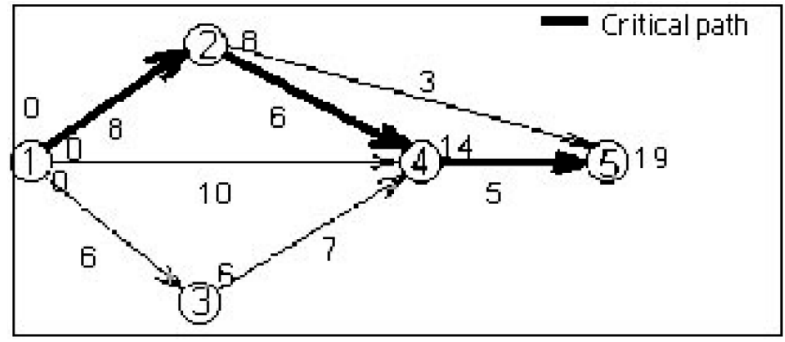

Fig. 2 CPM network diagram related to normal lead times

Let us suppose that the fix cost is 20000 thousand HUF for 19 weeks. The reduction of the lead time results in a savings of 1000 thousand HUF per week. In this case the programme with minimal total cost is the programme with minimal lead time, the total cost of the programme is 43850 thousand HUF (total variable costs) +20000 thousand HUF (total fixed costs) $-4 \times 1000$ thousand HUF savings since we were able to complete the project earlier. Consequently, the total cost $=43850+20000-4000=$ $\mathbf{5 9 8 5 0}$ thousand HUF.

The following chart demonstrates the possible solutions.

Table 2.1-1

\begin{tabular}{|c|c|c|c|c|c|c|}
\hline Activity & $\begin{array}{c}\text { Normal time } \\
\quad(\text { tnij })\end{array}$ & $\begin{array}{l}\text { Rush time } \\
\text { (trij) }\end{array}$ & $\begin{array}{c}\text { Normal cost } \\
\text { (C nij) } \\
\text { (thousand HUF) }\end{array}$ & $\begin{array}{c}\text { Increase in } \\
\text { costs/unit ( } \Delta \text { Cij) } \\
\text { (thousand HUF) }\end{array}$ & $\begin{array}{c}\text { Normal resources } \\
\text { demand (Rnij) } \\
\text { (person) }\end{array}$ & $\begin{array}{c}\text { Increase in } \\
\text { resource } \\
\text { demand/unit } \\
(\Delta \text { Rij) (person) }\end{array}$ \\
\hline$(1.2)$ & 8 & 6 & 4500 & 100 & 3 & 0.5 \\
\hline$(1.3)$ & 6 & 5 & 12000 & 200 & 2 & 1 \\
\hline (1.4) & 10 & 7 & 10500 & 150 & 2 & 1 \\
\hline (2.4) & 6 & 4 & 7500 & 300 & 4 & 1 \\
\hline$(2.5)$ & 3 & 3 & 3500 & - & 2 & - \\
\hline (3.4) & 7 & 6 & 1500 & 500 & 3 & 1 \\
\hline$(4.5)$ & 5 & 4 & 2500 & 650 & 1 & 1 \\
\hline \multicolumn{3}{|l|}{ Summary } & 42000 & - & - & - \\
\hline
\end{tabular}


Table 2.1-2

\begin{tabular}{|c|c|c|c|c|c|c|}
\hline $\begin{array}{c}\text { Number } \\
\text { of steps }\end{array}$ & $\begin{array}{c}\text { Reduced } \\
\text { activities }\end{array}$ & Reduction & $\begin{array}{c}\text { Total variable } \\
\text { costs (thousand } \\
\text { HUF) }\end{array}$ & $\begin{array}{c}\text { Increase in } \\
\text { costs/unit } \\
\text { (thousand HUF) }\end{array}$ & $\begin{array}{c}\text { Total increase in } \\
\text { variable costs }\end{array}$ & $\begin{array}{c}\text { Total } \\
\text { time of the project } \\
\text { (week) }\end{array}$ \\
\hline 0 & - & - & 42000 & - & - & 19 \\
\hline 1 & $(1.2)$ & 1 & 42100 & 100 & 100 & 18 \\
\hline 2 & $(1.2)+(1.3)$ & 1 & 42400 & $100+200=300$ & 300 & 17 \\
\hline 3 & $(4.5)$ & 1 & 43050 & 650 & 650 & 16 \\
\hline 4 & $(2.4)+(3.4)$ & 1 & 43850 & $500+300=800$ & 800 & 15 \\
\hline
\end{tabular}

Let us examine the case where the resources limit is 10 persons. Our available cost limit is 61000 thousand HUF. In the second case the resources limit is 11 persons. Our available cost limit is 59000 thousand HUF.

The following table shows the activities which have alternative solutions.

Table 2.1-3

\begin{tabular}{|c|c|c|c|c|c|c|c|c|}
\hline & $(1,2)$ & & & $(3,4)$ & & & $(4,5)$ & \\
\hline$q$ & $v c / \Delta v c$ & $r / \Delta r$ & $Q$ & $v c / \Delta v c$ & $r / \Delta r$ & $q$ & $v c / \Delta v c$ & $r / \Delta r$ \\
\hline 100 & $4500 / 100$ & $3 / 0.5$ & 100 & $1500 / 500$ & $3 / 1$ & 100 & $2500 / 650$ & $1 / 1$ \\
\hline 90 & $4000 / 90$ & $2 / 0.5$ & 90 & $1000 / 90$ & $3 / 1$ & 96 & $2500 / 600$ & $1 / 1.5$ \\
\hline
\end{tabular}

where $q$ is the quality factor. When employing this method we do not have to use figures for the quality factors by all means. It is enough to arrange the alternative solutions in order of quality. We can, however, determine the target function easier when, according to some principle, we assign a quality factor to the alternative solutions.

If the quality of the implementation of some activities needs special attention then it is practical to designate our target function used for selection in a way that we weigh the quality factors of these important functions.

Let us examine the following case where the resource limit is 10 persons. Our available cost limit is 61000 thousand HUF. The resource-loading diagram for 15 weeks is as follows:

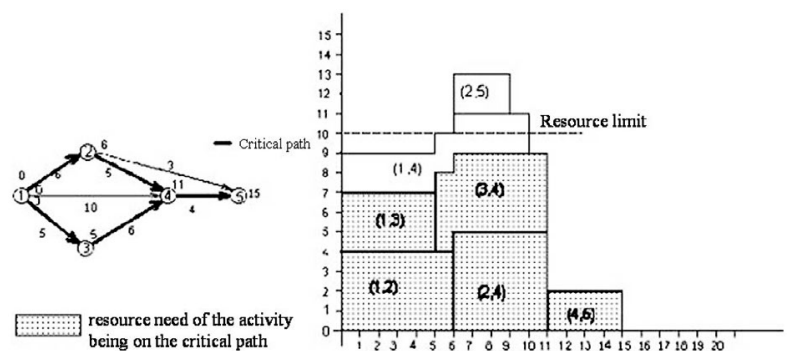

Fig. 3 Loading diagram related to the shortest lead time of the project (there is not any non-critical solution here)
On the loading diagram we can see that there is no non-critical solution. In order not to overstep the resource limit let us choose the 3 rd production programme from the solutions obtained by $\mathrm{CPM} / \mathrm{COST}$

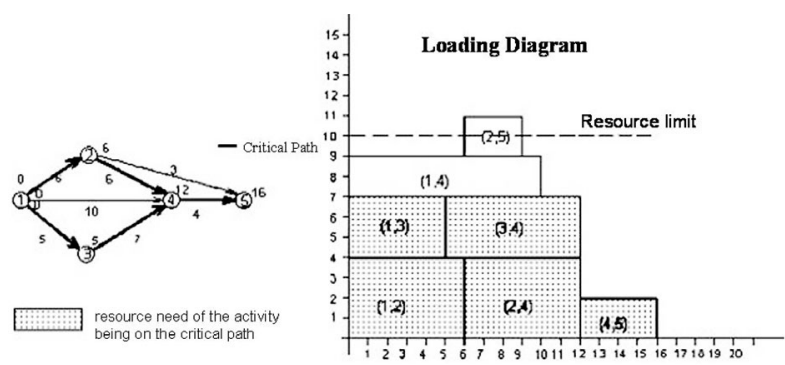

Fig. 4 Loading diagram related to a longer lead time
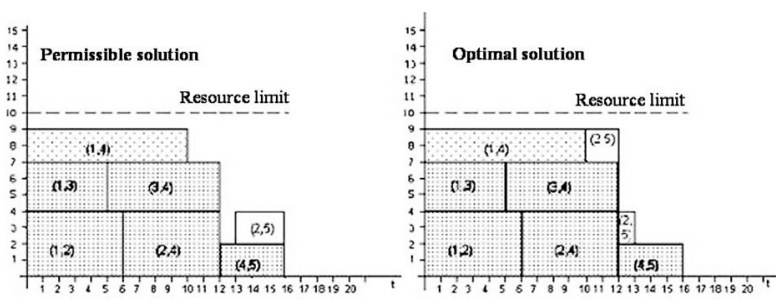

resource need of the activity being on the critical
path

activity unmoved for the search of the permissible
solution

Fig. 5 Non-critical permissible and optimal resource allocation

During the determination of the optimal resource allocation the objective was to achieve a start as early as possible. At that time we did not have to reach a compromise concerning quality. The total cost: 43050 thousand HUF (total variable costs) +20000 thousand HUF (total fixed costs) - 3000 thousand HUF (savings in fixed costs due to the shorter lead time) $=60050$ thousand HUF $<61000$ thousand HUF (budget).

Unfortunately, in the second case we have to carry out the activity(ies) at a lower quality level in order not to overstep the limit of the planned costs. 

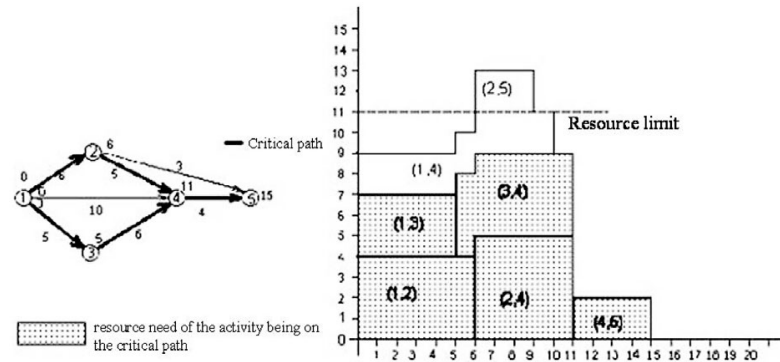

Fig. 6 Loading diagram related to the shortest lead time of the project

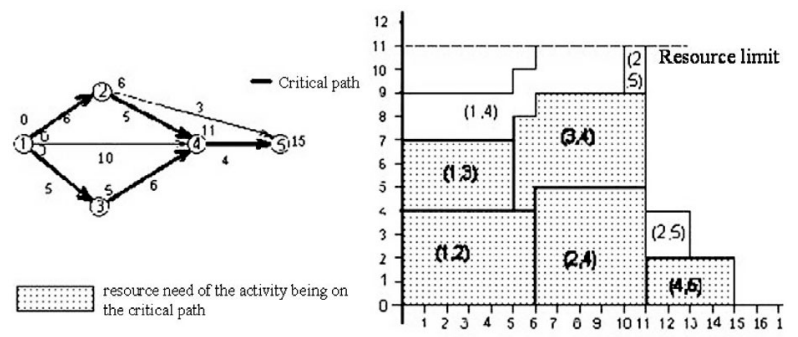

Fig. 2.1-6 Optimal resource allocation
The total cost is 59850 thousand HUF as calculated earlier which exceeds the 59000 thousand HUF budget. If the $(3,4)$ activity is replaced by an alternative one then the resource need and the lead time remain unchanged but the cost is reduced by 900 thousand HUF. In this case the total cost will be 58850 thousand HUF which is less than the available budget.

\section{Summary}

The tougher the competition for the implementation of a project, the greater the chance that we have to implement the project at a low price which does not cover our expenses. Companies are often not fully aware of the costs of the implementation of the given project and frequently undertake the realization of the project and find out only later that their expenses will be much higher than their preliminary estimation.

If the contractual incomes do not cover the expenses then we either give up this business or undertake it even if we know that we can realize the project with a loss or try to replace the activities by alternative solutions. In such a case we should take into account that the activities are to be implemented at the highest possible level.

\section{References}

[1] ANDRÁSFAI, B.: Graph theory, Polygon, Szeged, 1997, pp 1-131

[2] KAUFMANN, A.: Methods and Models of the Operational Research, Technical Publishing House, Budapest, 1968, pp 11-123

[3] BENCSIK, A.: Methodology of Organizational Techniques, University Press, Veszprém, 1998

[4] CHRISTOPHIDES, N.: Graph theory, An Algorithmic Approach, Academic Press, New York, 1975

[5] DERIGS, U.: Programming in Network and Graphs. Lecture Notes in economics and Mathematical Systems. Vol. 300. Springer Verlag, New York, 1988

[6] KOSZTYÁN, Z., BENCSIK, A., HOGYOR, A.: Optimal Resource Allocation of Active Projects, Verlag Dashöfer, 2002

[7] KOSZTYÁN, ZS., BENCSIK, A.: Optimal Resource Allocation of the Projects with Uncertain Lead Time, Verlag Dashöfer, 2003

[8] KOSZTYÁN, ZS., BENCSIK, A.: Handling of Uncertainty in case of Different Logistical Tasks, Verlag Dashöfer, 2002

[9] PAPP, O.: Employment of Network Programming Methods in Practice, Economic and Legal Press, 1969

[10] AHUJA, R. K., MAGNATI, TH. L., ORLIN, J. B.: Network Flows, PRENTICE HALL, Upper Saddle River, New Jersey 07458 1998, pp 24-46, 108-116, 135-154, 177-196, 469-173, 520-528

[11] RÓNYAI, L., IVANYOS, G., SZABÓ, R.: Algorithms, Typotex, Budapest, 1998, pp 110-183

[12] SZENDREI, Á.: Discrete Mathematics, Polygon, Szeged, 1996, pp 63-68, 295-324

[13] COHEN, TH. H., LEISERSON, CH. E., RIVEST, R. L.: Algorithms, (Technical Publishing House), Budapest, 1997, pp 392-543

[14] TÓTH, I.: Mathematics for Business Administrators - Operational Research I, Textbook Press, Budapest, 1987, pp 167-189. 